\title{
Computational Design
}

Research in Architecture:

The Legacy of the

\section{Hochschule für}

Gestaltung, Ulm

Isabel Clara Neves, João Rocha and José Pinto Duarte 


\section{Computational Design Research in Architecture: The Legacy of the Hochschule für Gestaltung, Ulm}

Isabel Clara Neves, João Rocha and José Pinto Duarte

The use of computational processes in architecture is a widespread practice which draws on a set of theories of computer science developed in the 60s and 70s. With the advent of computers, many of these methodologies were developed in research centres in the USA and the UK. Focussing on this period, this paper investigates the importance of the German Hochschule fur Gestaltung, Ulm (HfG) design school in the early stages of computation in design and architecture. Even though there were no computers in the school, it may be argued that its innovative pedagogy and distinguished faculty members launched analogical computational design methods that can be seen as the basis for further computational approaches in architecture. The paper draws on archive material, as well as at an original interview with Tomas Maldonado, to propose that the remarkable work pursued by Tomas Maldonado (the educational project), Max Bense (information aesthetics) and Horst Rittel (scientific methods) was fundamental in establishing HfG Ulm as the forerunner of computation in architecture. 


\section{INTRODUCTION}

Albert Einstein was born in Ulm on March I4 1879 and decades later the city would remember this by associating the motto Ulmenses sun mathematici (the people of Ulm are mathematical) with its famous son. Was it just coincidence that one of the most significant design schools since the end of World War II, the HochschulefürGestaltung, was founded in Ulm and that during its existence (1953-1968) its three directors were the Swiss architect Max Bill (who had been one of Hannes Meyer's students at the Bauhaus), the Argentinean painter Tomas Maldonado, and the German philosopher Max Bense? In the 60s computers were only available at a few research centres, many located in engineering departments. However, their capabilities were widely recognised and the subject of much broader theorisation and influence, opening up the field of logic and computer science to the social sciences and arts.

By the mid 60s some research centres were engaged in research that applied advances in computing to architecture and planning. The pioneering institutions in this field were the Land Use and Built Form Studies Centre (LUBFS) at the University of Cambridge in the UK, the Centre for Configurational Studies at the Open University, Milton Keynes, and the Design Methods Movement at the Royal College of Art in London, and the Architecture Machine Group at MIT and Design Research Center at CMU, in the USA [I] (see figure I). However the initial line of inquiry concerning the interrelation between science and design (architecture) had begun earlier at the Hochschule für Gestaltung in Ulm.

The HfG had no access to computer systems but was, nevertheless, extremely important to the beginnings of the computer era in architecture. In this regard, Kenneth Frampton has noted that the HfG had little choice in

Figure I: Some important research centers that marked the emergence of the computational era in architectural field. Source: image held by the author.

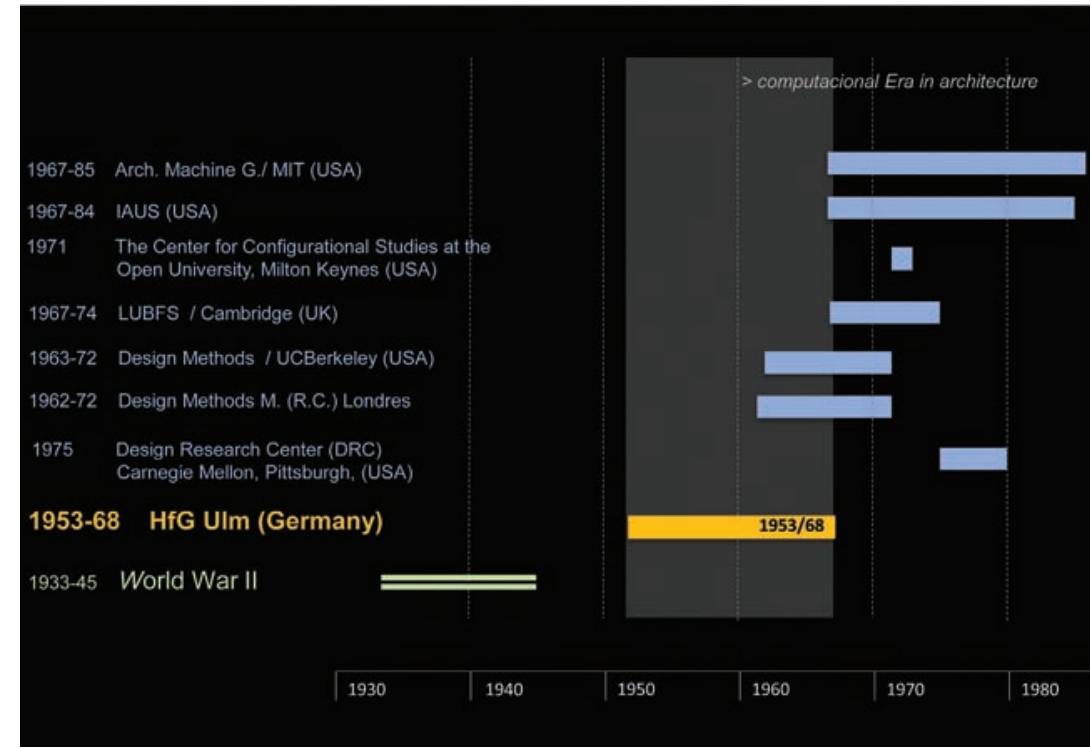

Computational Design Research in Architecture:The Legacy of the Hochschule für Gestaltung, Ulm 
the 50s other than to look beyond the limits of the established traditions for a mediatory ideology from which it could develop not only a satisfactory heuristic method, but also a theory of design [2].

In short, this paper traces the contribution of the HfG Ulm as a theoretical and pedagogical influence on the introduction of computation to architecture, a history which has not been studied in detail and is not yet well-known.

\section{THE HFG ULM - THE EDUCATIONAL PROJECT}

The Hochschule fur Gestaltung Ulm (see figure 2), which was founded in 1953 and functioned until 1968, survived the transition from industrial to post-industrial society. In spite of its short existence, Ulm reflected the continuing post-war project of rethinking the role of social science within a faith in the enlightened supremacy of reason. Its investigative quest for 'good design' originated as a moral project with a firm belief in aesthetics as means towards a democratic society, owing much to the personal history of its founders during the Nazi Resistance era.

The School was founded in memory of Hans and Sophie Scholl who had been executed by the National Socialists in 1943 for their involvement in the Rosa Branca resistance group, which openly criticised National Socialism in defiance of the law. In 1953, in an explicitly antifascist gesture, Inge Scholl, the sister of the deceased young couple, worked with Olt Aicher to develop the concept for a cultural centre in Ulm which would invest in education, politics and antifascist culture with the aim of creating and running a school in which professional training, artistic creativity and cultural activities would be combined with political responsibility. They also invited the Swiss painter, publicist, sculptor and architect Max Bill, to help found the School.A former student of Walter Gropius and Hans Meyer at the Bauhaus in Dessau from 1926 to 1929, Max Bill had kept in touch with the Bauhaus teachers, including Gropius, and had also worked for the Education Board for the occupying forces and was trusted by them. His work as an architect and designer, his international experience and contacts, and his irreproachable political past made him the perfect addition to the team planning the new Ulm School.

In this way the programme for a "free school for culture and politics" was drawn up to ensure the education of a "liberal German and European youth" and thus continue to develop resistance to any antidemocratic and fascist tendencies. As historian Jörg Petruschat stated, the radical nature and continued importance of the problems and questions that were addressed at the School can only be understood within the broader historical context of cultural, artistic, scientific, and technical developments. The objective of the Ulm School of Design was to improve the relationship between education, science, industry and design, within a new praxis. This was a far more ambitious and lofty goal than merely creating good design and, in 
terms of the path that was taken and the means that were used to transform modern society into a more humane world, the Ulm School of Design was more than just an historical precedent [2].

In one of the few critical texts that addresses the contribution of the HfG, Kenneth Frampton says:

"There is little doubt that HfG has been the most significant school of design to come into existence since the end of WWII, not so much for what it achieved in terms of actual production, nor for the large number of designers it effectively educated, but finally for the extraordinary high level of critical consciousness that it managed to sustain in its daily work". [3]

Although it has not been studied in depth, the output from this educational project was significant, both on a practical level, through collaboration with various companies such as Braun, Olivetti Design, Lufthansa, and on a theoretical level, as seen in the journals where the results of its systematic teaching was shared. The Ulm Journal was the official periodical of the HfG and its design reflects the attitude of the HfG (see figures 3 and 4). The Journal was launched in 1958 to inform politicians and economists of its activities and the texts written mainly from Tomás Maldonado and Gui Bonsiepe. It may be considered one of the greatest contributions to design education in the 50 s and 60 s, offering examples of practical work produced in various school departments and theoretical articles that reveal a strong impetus towards developing design as a research-based activity.

The teaching at the HfG Ulm explored a scientific approach, integrating systemic and objective methods of collecting and processing data in order to inform the design solution. It would synthesise science and design in a new scientific humanism that recognised the pluralism of methods and methodological perspectives required by the designer to address the new problems of industrial culture. What also emerged, however, were the beginnings of an operational view of design science - what Maldonado sometimes called "scientific operationalism" - drawing on an eclectic combination of particular methods from a number of disciplines. Nowhere were designers more focused on the question of "utter devastation", yet with an "unlimited curiosity" about all the new scientific disciplines and new ideas emerging in the philosophy of science and mathematics [4]. As Maldonado stated, the mainspring of all their curiosity, reading, and theoretical work was the determination to find a solid methodological basis for design work [5]. In this way, scientific knowledge and new methods could be applied to the search for solutions to design problems in an industrialised environment.

As summarised by René Spitz, a leading author on the subject, the HfG Ulm had three main characteristics that distinguished it from other design schools. Firstly, its work was based on the issue of the social responsibility of designers. Secondly, it invested in a strong impetus towards developing 


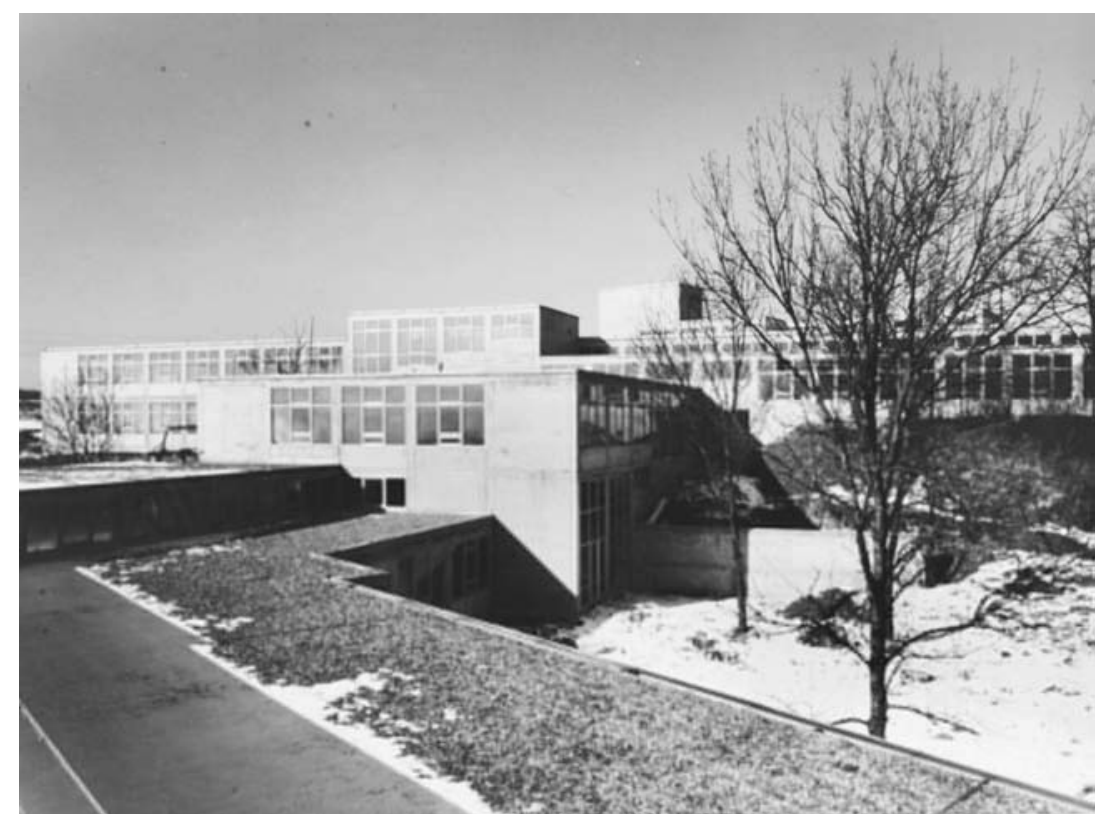

design as a research-based activity. Thirdly, the HfG Ulm integrated all disciplines, from the humanities, engineering, science, politics and economics as well as those related to design. The designer had to work as a member of a team rather than an artist [6]. All of these issues, in one way or another, distinguished it from its predecessor, the Bauhaus.

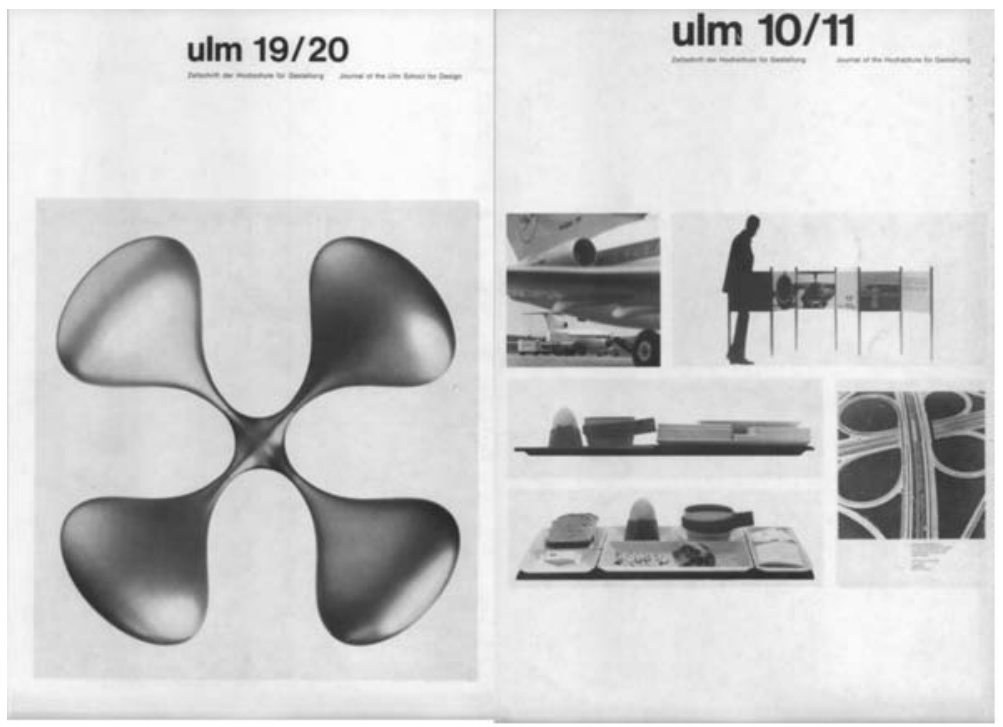

Figure 2 Hochschule für Gestaltung (HfG) Ulm / Ulm School of Design (1953-1968). Architect: Max Bill. Date 1955 Source Sammlung René Spitz
4 Figures 3 and 4: Covers of the HfG Ulm Journal;

Source: HfG Ulm archive, personal photographs, March 2012 


\section{THE SCIENTIFIC APPROACH OF TOMAS MALDONADO}

This paper identifies the three most visible areas that became significant at the HfG Ulm. First and foremost was the ideology, or pedagogical project (Tomas Maldonado), secondly, the philosophy, or information aesthetics (Max Bense) and thirdly, the methodology, or scientific methods. These three areas contributed towards creating the innovative scientific approach to design that characterised the school. The focus of analysis in this article is the scientific component of the teaching, pursued in particular by certain professors at the Ulm School. It begins with an analysis of the work of Tomás Maldonado, whose education project was decisive in establishing the scientific approach in the school, mainly in three areas: the teaching of fundamentals, the semiotics course, and the idea of scientific operationalism.

\section{I Ideology: the pedagogical project}

The ideology which emphasised the artistic dimension, a legacy of the Bauhaus pursued by the first director of the HfG, Max Bill, was replaced by the multidisciplinary scientific approach advocated by his successor, Tomás Maldonado. He was a painter who had been actively involved in the Concrete Art movement in Argentina in the 1940s and his theoretical interests focused on the philosophy of science and technology. At the HfG Ulm, he became the director and individual responsible for the educational project during the second phase of the School, when different subjects, such as economics, sociology and mathematics, operational research, statistics, set theory, linear programming techniques, cybernetics and those associated with the history of science and the theory of machines created a dynamic that led to the emergence of this new School project.

\subsection{The Teaching of Fundamentals}

Tomas Maldonado had an important influence on the construction of the "teaching of fundamentals". Anticipating the role of industrialised production methods, information theory, cybernetics, and computer theory, the essential didactic thrust of the HfG came from the teaching of fundamentals, namely visual methodology, means of representation, methodology and perceptual understanding, which provided an introduction to the main problems of perception. The newly established objective of the foundation course was the introduction of rigorous methods, in which mathematical equations and their translation became the focus of interest in the exercises presented by Tomas Maldonado. In 1963 he wrote that Joseph Albers had taken upon himself perhaps the most difficult task in the development of the Bauhaus preliminary course, which he had solved brilliantly: in other words, he had transformed the different and partly contradictory components (pedagogical activism, mystical expressionism and exaggerated 
constructivism) into a systematic, coherent and operable teaching subject [7]. Maldonado reaffirmed Albers's basic design model, as it appeared in its final form - avoiding any stress on semantic issues, the materialisation involved in the applied design process, pragmatic issues and the appraisal of the usefulness of the design product -and dealing mainly with the syntactic issues of design, namely shape, colour, and texture. However, he made a significant contribution to the model by supplementing the visual training component of the basic course with interdisciplinary content, i.e. with abstract fields of knowledge that extended beyond accepted formal design issues. Maldonado stated that the Bauhaus didactics, particularly in the preliminary course, were a matter of emphasising expression, intuition and action and, above all, "learning by doing”.

He expanded this with lectures on symmetry and topology and studio assignments linked to these topics. The other interdisciplinary field of knowledge that Maldonado introduced was perception, particularly Gestalt psychology. He picked up on Gestalt and depth perception and presented both in a comprehensive manner, far more thoroughly than Albers had done, and his guidelines for exercises that involved perception were more elaborate those which addressed symmetry and topology. His subsequent straightforward coverage of Gestalt at the HfG reflected his objections to “impregnating” knowledge. In his HfG basic course, Maldonado's lectures introduced non-visual fields of knowledge, including ergonomics and semiotics [8].

In 1955 Maldonado stated: "The point of the basic course is to overcome the opposition between pure knowledge and habitual action. From the basis of practical experience and allied systematic investigation, the theoretical bases of new methods of design will be laid". [9] The changes were already apparent in the 1955/56 foundation course, as the new principles formulated by Maldonado were put into practice (see figure 5). In particular, Maldonado's course attempted to incorporate mathematical knowledge into design, elaborating on early versions of fractals such as the Sierpinski Triangle, the Peano or Hilbert Curve, which expressed the tension between the finite and the infinite (see figure 6).

Maldonado's research first explored relationships between parts and the whole and the whole and its parts, a discourse informed by Gestalt theory. Later, he reflected on the arrival of the digital and the digitalisation of images. Much of the work at the HfG, in particular on the foundation course taught by Maldonado, was produced by systematising the principle of points in a grid (see figure 7). As he stated in an interview given specifically for this research:

"My contribution was important due the formative disciplines, such as cybernetics and information theory. The computer was emerging, but there was no computer at that time. We had no experience of the computer then. (...) In the first year, students 
were still linked to the fundamental course in elementary school, and I think the important question and contribution was how to set and change the fundamental course at the Bauhaus to one that assimilated these new concerns (...). This was the idea of how images could be created from the way in which their elements behaved. The model for producing an image was a grid of small dots with different diameters. This very elementary idea allowed us to manually simulate what could later be done with computers. The students were asked to produce such images in incredible detail, which was extremely difficult. Here the insight into what would become computer use was clear, but in our case it was produced manually... it was crazy". [10]

It was a powerful intuition, as the development of computer and automation technologies subsequently confirmed, above all after 1963. For Maldonado, there was no doubt that the idea, for example, of arriving at a kind of symbiosis between calculus and graphic representation in the resolution of problems, which engaged many people during the 1950's, formed the basis of the still expanding use of computers. In fact, Maldonado was not only developing his VisuellEinffuhrung (introductory visual training), but also exploring diverse ideas that later shaped the curriculum of the School as a whole. By 1959, he had revived the HfG Ulm Journal, in which HfG ideas could be disseminated to a wider design community of academics and professionals, with the upshot that many of the HfG 's innovative curricular topics began to appear in a variety of places.

Tomas Maldonado conceived of a new kind of basic course which involved a more scientific approach. The emphasis remained on nonorientated objects and Albers' register was preserved, but the main focus involved working and designing on the basis of a theoretical understanding of perception and mathematical theory. "Visual methodology" was the main subject on the foundation course in this second phase. The objective was to train students to consciously manipulate and control design processes. The new basic course, later known as the "Ulmer Modell", included the following scientific disciplines: perception and Gestalt theory, concepts of symmetry and topology. William S. Huff, an American student and later a teacher at the HfG Ulm, described the concept of the Maldonado basic course in an interview:

"Maldonado arrived in Ulm in the second year. Then he began to think about the best ways of creating the "Grundlehre" (basic course). In the third year, 1955/1956, he was responsible for teaching the "Grundlehre". He carried on with what might be called a refinement and renovation of the Bauhaus line. He preserved what Albers had done at the Bauhaus but at the same time offered something else: he made it interdisciplinary. He added in other subjects, such as symmetry, topology and Gestalt theory. 
He introduced information on these subjects into the course, something Albers had not done. Maldonado valued the theoretical and historical background to their origins." [I I ]

Another example of a mathematical approach with direct applications for design work, in this case architecture, involved Anthony Froshaug, who came from London to teach at the Visual Communication Department in the HfG Ulm from 1957 to 1960. In 1959 he taught "Visual Methodology" on the foundation course. He stated that the objective of his basic course was to foster a systematic working method in which students had to work with grid patterns, first in two dimensions and later in three (see figure 8). The general idea of graphs was developed through an understanding of grids. Froshaug used the example of a ground floor plan of a Le Corbusier house in La Plata in 1954 (see figure 9) to explain the role of graphics in visualising circulation. After finishing the building, Le Corbusier had to remodel the house, since the rooms were badly arranged. Froshaug suggested entering the possible forms of circulation into a matrix, after numbering the rooms. The maximum number per line was 5 . Therefore a grid in which at least five lines met at each point was required. From the range of grids shown in Figure 10, type 3.6 was selected as suitable.

Fröshaug used graphs to represent and analyse existing situations, highlighting their "operative character in their constructive use in solving problems." Graphs appeared to Fröshaug to be the most suitable tool for presenting relationships, thus representing the topological connections between spaces. He hoped, by "cataloguing different design options with graphs, to arrive at a complete overall view of the design possibilities and even a rough design." [12]
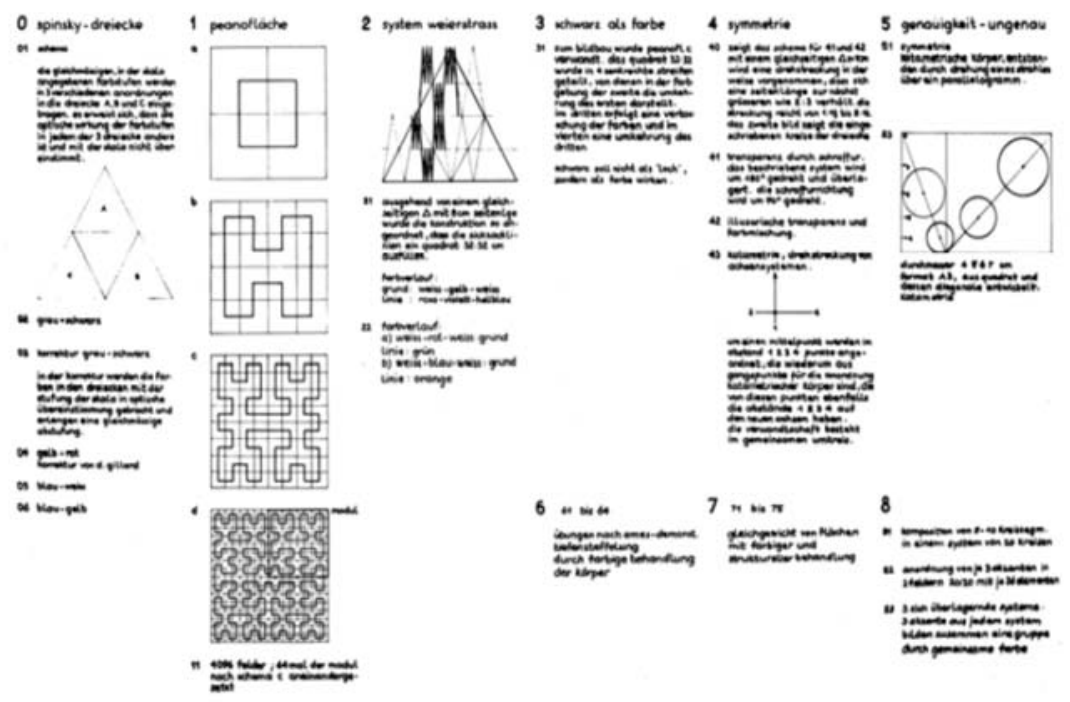

Figure 5: Course assignment, Student: Klaus Franck, Professor: Tomás Maldonado, 1955-1956. Source: Herbert Lindinger, ed., Hochschule für Gestaltung Ulm, Ulm Design: The Morality of Objects, transl. David Britt (Cambridge: MIT Press, 1990), 44. 
Figure 6: Sequence of Sierpin'ski Triangle

Source: page 3I Ulm nol2/I3, March 1965

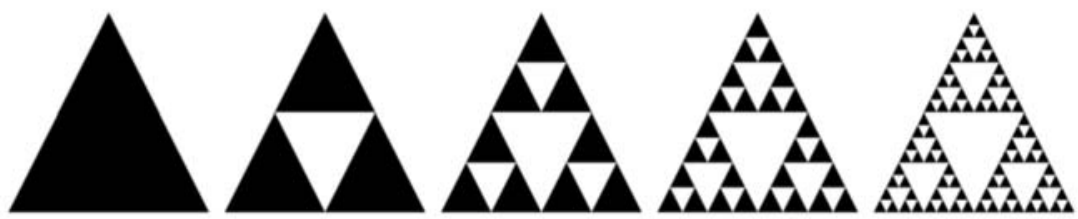

Figure 7: Exercise "Raster, Square Lattice", Students: Gerald Weismann (1964) Charles First (1963) and Fred Watts (1963) Professor:Tomás Maldonado, 1955-1956.

Source: page 31 Ulm no I2/13, March 1965, p. 12.
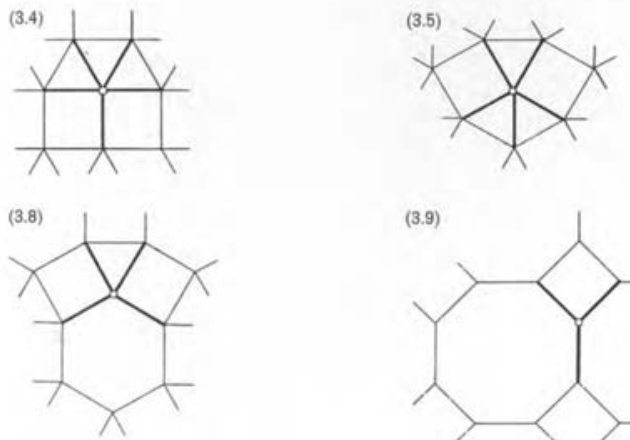

(3.9)

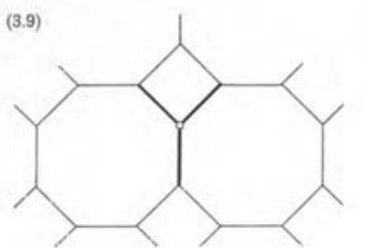

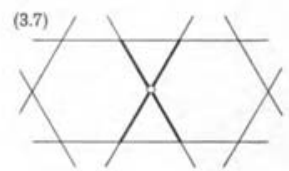
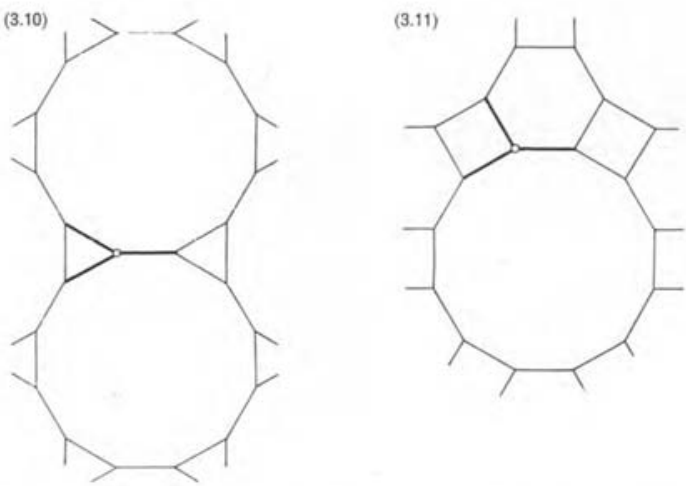

A Figure 8: Patterns and Grids (Froushaug 1959: 2-3)

Source: Ulm 4/5 (September 1959): 59. 


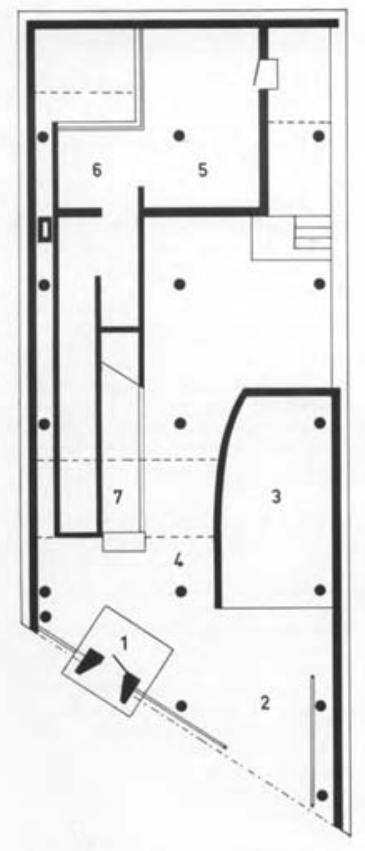

(6.1)

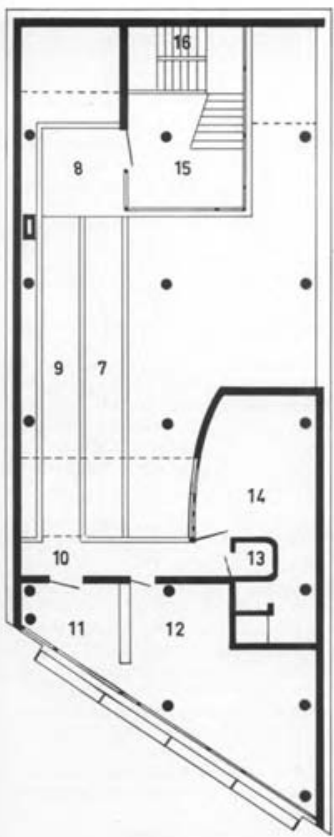

(6.2)

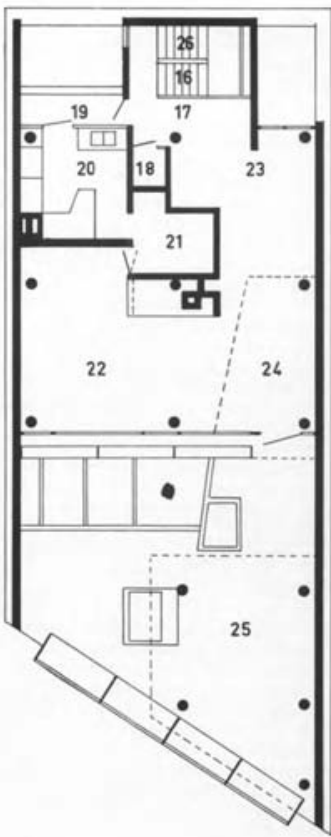

(6.3)

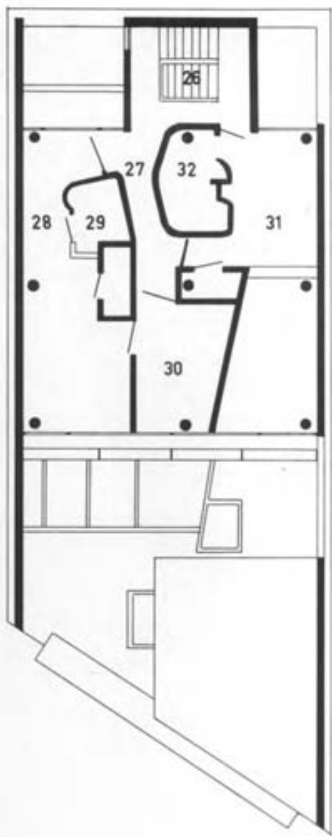

(6.4)

A Figure 9: Floor plans of the Casa Curutchet in La Plata, designed and built by Le Corbusier in 1954 (Froushaug 1959: 7) Source: Ulm 4/5 (September 1959): 62.

$\begin{array}{lllllllllllllllllllllllllllllllll}1 & 2 & 3 & 4 & 5 & 6 & 7 & 8 & 9 & 10 & 11 & 12 & 13 & 14 & 15 & 16 & 17 & 18 & 19 & 20 & 21 & 22 & 23 & 24 & 25 & 26 & 27 & 28 & 29 & 30 & 31 & 32\end{array}$

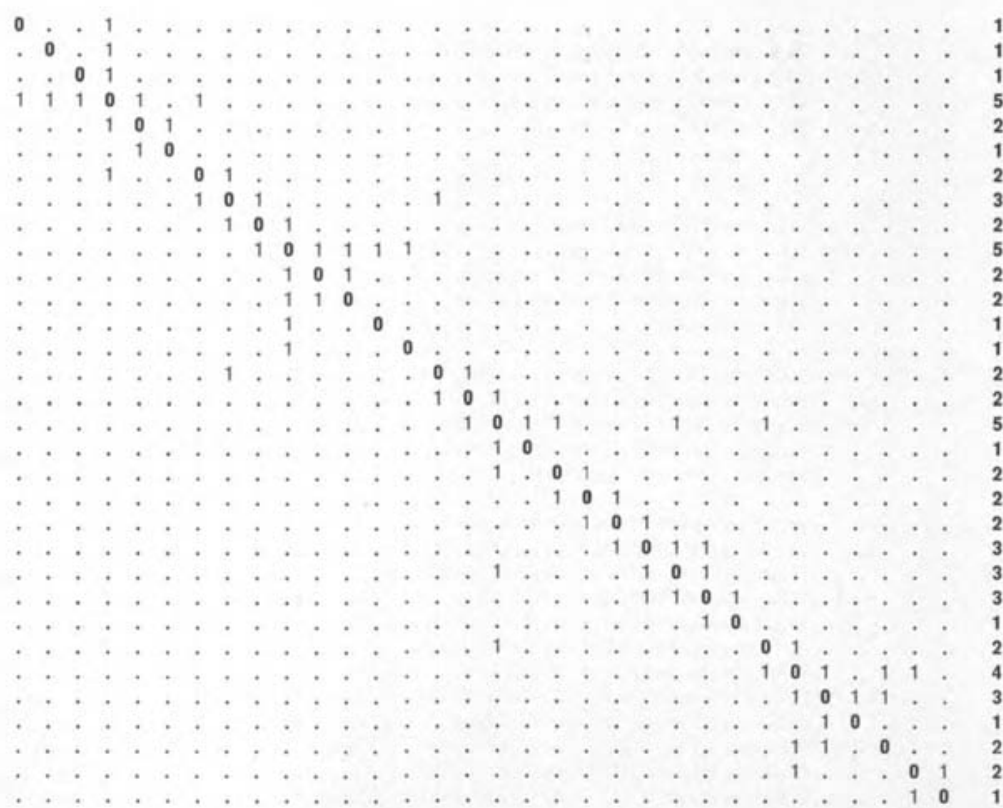

4 Figure 10: Matrix and graphs for circulation (Froushaug 1959:7-8) .

Reproduced with kind permission of Gui Bonsiepe, Ulmer Texte.

Source: Ulm 4/5 (September 1959): 63. 


\subsection{Scientific Operationalism and Semiotics}

Maldonado was also one of the first to recognise that the progressive aspects of the Bauhaus-oriented practical experience were the opposite of the verbal emphasis of the humanist tradition. He clearly recognised that rapid technical and economic developments presented new demands for teaching industrial design. From this point of view, the educational style of the Bauhaus had become obsolete, since the assumptions had been formulated on the basis of art, not science. In an interview given as part of this research (see figure $\mathrm{II}$ ), Maldonado stated that in the late 50 s and early 60 s the main concern was the drawing methods, since the Bauhaus methods were different and much more intuitive and artistic. He notes:

"We were interested in all the serious and rigorous methodology. Our methodology later became a sort of "methodolatry" and it created a series of problems. I realised that because I was on the Board. There was a controversy between professors and students increasingly motivated by this issue of methodology. I observed this whole progression of the methodology, and I supported it. I had to react against this obsession with method. I realised that the process was becoming increasingly abstract, because things were exaggerated, since one could not speak of things normally. However, evidently in its early stages the more rational and not exaggerated methodological contribution was influential because it made issues of method throughout the project more objective. It allowed for a confrontation between relationship and industry, providing a more objective mindset to face things with, rather than simply design as a matter of taste." [10]

The distance from Bill's interpretation of Bauhaus pedagogy was most obvious in the theoretical courses which were required to teach the new methodologies. These were based, on the one hand, on mathematical "operational analysis" and on the other hand, on the history of science. Originating in military efforts before and during World War II, operational analysis was defined as a scientific method of providing executive departments with a quantitative basis for decisions regarding the operations under their control [13].

Subsequently, operational analysis techniques were used to solve problems in a variety of industries. Since it was interdisciplinary, the problem-solving techniques and methods used tools such as statistics, optimisation, probability theory, graph theory, decision analysis, mathematical modelling and simulation.

Nevertheless, it was clear that there had to be another approach, a new philosophy of praxis. To this end, Maldonado proposed scientific operationalism as the foundations of a new educational philosophy which was no longer concerned with the names of things, or things in themselves, but with real knowledge [14]. Maldonado was referring hereto the 
philosophical system developed in the early '50s by Anatol Rapoport and published in 1953 under the title Operational Philosophy in which Rapoport had attempted to provide an accurate system for the evolution of alternative actions, stating that operational philosophy focuses on objectives. Maldonado saw a solution for introducing a "scientific thinking operation" that would lead to an objectivist-experimental methodology. It provided the opportunity for a new philosophy of education based on scientific operationalism and directed towards overcoming the dichotomy between theory and practice. In 1958, Maldonado stated that the technologised world and industrial society were so difficult to comprehend that it was impossible to manage without new working methods. He believed it was no longer possible to gather information without understanding and approaching disciplines that enabled the maximum possible amount of information to be accumulated, and this convinced him of the need to incorporate a new dimension into the teaching plan. Maldonado called this the methodological dimension, noting that the students had already been introduced to the fundamental teachings of mathematical logic [15].

Lionel March the founder, with Leslie Martin, of the Land Use and Built Form Studies, University of Cambridge School of Architecture, says that the analytical approach with which the Ulm School became identified gave way, in the mid' 60 s, to heuristic procedures related to the increasingly seductive power of the modern computer [16]. It is important, however, to stress the fundamental attitude that nurtured the philosophical epistemology of the Ulm School. On the one hand, it was grounded in the legacy of positivism, very much embodied in the work of the Austrian philosopher Rudolf Carnap (I89I-1970) one of the members of the "Vienna Circle", and the early philosophy of Charles Pierce (1839-19/4), associated with semiotics. On the other hand, it was rooted in the need to critique the Anglo-Saxon philosophy of everyday language and systems theory.

By 1956 Max Bense had already "paved the way" for semiotics and literature on the theory of signs to be introduced into classes, largely in the service of aesthetic information, focusing on Charles Pierce's categories of aesthetics and ethics. Semiotics was Maldonado's effort to put his "scientific operationalism" at the forefront of design, partly in opposition to the views of Max Bill, namely that the designer was a kind of aesthetic coordinator of cultural artefacts, and the Ulm School was the first design school to recognise this [16]. One year after Maldonado became coordinator of the HfG Ulm, he effectively introduced semiotics into the curriculum. As he said:

"Our interest, especially mine, was to understand what was happening in the world of information and communication. The first thing that caught our attention and struck me over the years was cybernetics. We were not only concerned with the semantic function. Today we no longer speak about cybernetics. I was the first professor of semiotics in the world and the HfG Ulm 
programme the first in which a discipline called semiotics appeared in design. Now, everyone is talking about semiotics, semiology etc. Then, the concern was to link the computerisation of the communication process to the programme, not only as management signs, but as signs and symbols".[10]

In 196I, as part of his contribution to semiotics, Maldonado published the definitions of 94 "Semiotic Terminology" items (see figure 12). These definitions were intended to serve as a set of analytical tools, enhancing semiotic discourse in design. Subsequently, Maldonado's students added rhetorical concepts and applied them widely to description and visual phenomena, thus concretising the idealised educational project for the HfG Ulm. Maldonado explained that the glossary was the result of the seminars on semiotics he had coordinated from 1957 to 1960 at the HfG Ulm. The starting point for these interdisciplinary studies was the writings of Charles W. Morris (I90I-1979), a leading representative of U.S. scientific philosophy who could be regarded as a founder of modern semiotics and one of the first to attempt to systematise semiotic philosophy [17]. At the International Congress of Scientific Philosophy (Paris, 1935), C.W. Morris explained the need to establish a link between all disciplines interested in the problem of meaning. This work was carried out by semiotics, i.e. the theory of signs.

Maldonado and Gui Bonsiepe wrote articles for the Ulm Magazine and developed practical work, such the symbol system for electronic data processing machines known as the ELEA 9003 Computer System (see figure 13). This project consisted of designing the alphabet for a new system of signs: approaches to the combination of theory and practice can be seen in the contract issued by Olivetti, the manufacturer of typewriters and computers, for developing a semiotic system. The task consisted of analysing existing sign systems and developing a new design codes for electronic data processing machines. It included the development of a non-grammatical design codes and involved developing a building block system for lamp holders, buttons, symbol carriers and the structures that supported these components. The authors explained the ELEA 9003 project in the following way:

"The design of the sign system: at first an inventory of signs, an alphabet was created. This contained the elements that could be combined to represent the various references. The alphabet consisted of two classes of signs: basic signs, comparable to the nouns in a language, and determinatives, like adjectives and verbs. The referents of the basic signs are the functional units of a system - that is, magnet strip, punch hole writer, disk memory. The referents of the determinatives are mostly states and processes carried out by the machines; that is, "ready" "compare", "functioning". The square was used as the fundamental geometric form for the basic signs. These were mainly planar, whereas the 
determinatives were linear, and there were syntactic and semantic relationships between both classes of sign. The sign for "writing", for example, was incorporated into the sign for "punch tape writer" and the sign for "reading" was the reverse of "writing" in order to make them easier to recognise". [18]

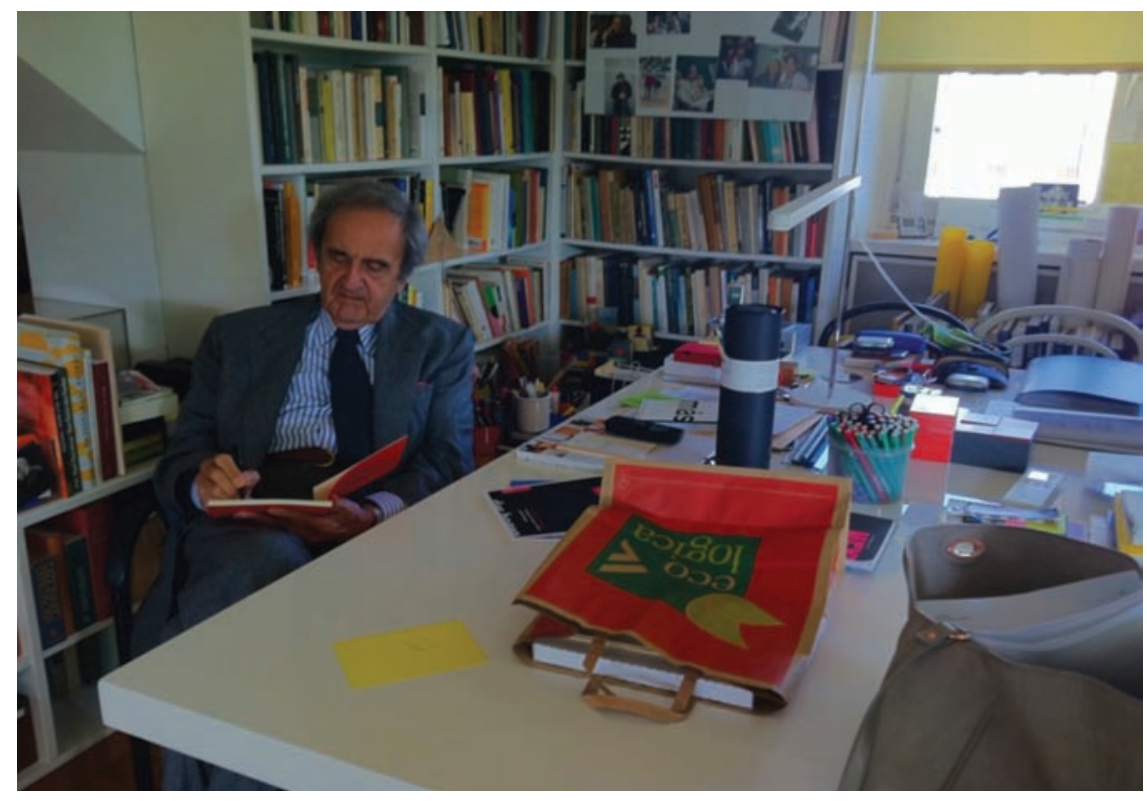

Figure II:Tomas Maldonado being interviewed by the author. Source: author's personal photograph, March 2012 (published with the interviewee's permission).

Figure I2:Tomas Maldonado 1959/60: "Glossary of Semiotics" in Uppercase 5 HFG Ulm. Edited by Theo Crosby. London:Whitefriars Press Tonbridge Kent.

Source: HfG Ulm archive, personal photograph, March 2012.

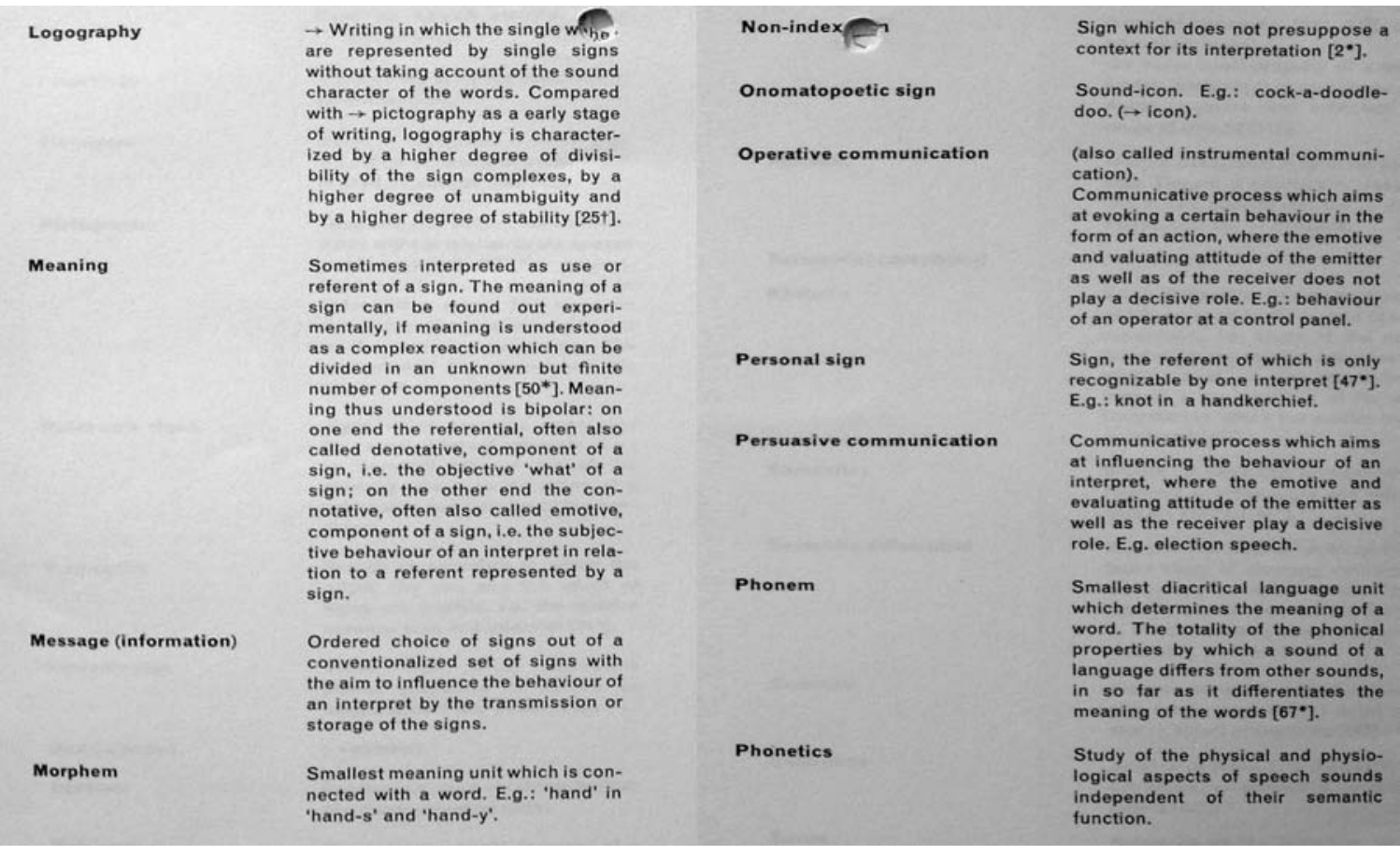




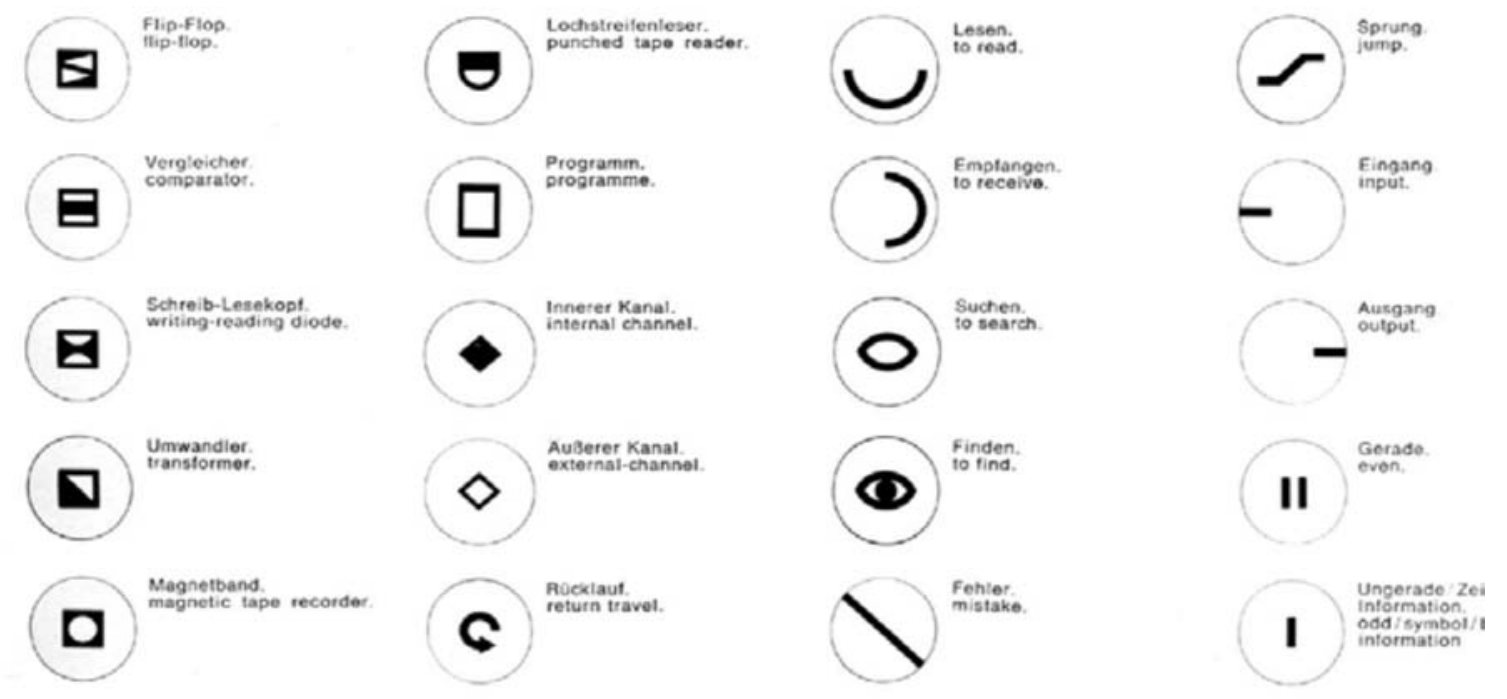

$\Delta$ Figure 13: ELEA 9003 Computer System, design for the alphabet of a new sign system: Design:Tomás Maldonado, Gui Bonsiepe for Olivetti S. p. A. Milan. (1960/6I).

Source:Ulm 8/9 (September 1963): 20$24,22$.

\section{PHILOSOPHY: INFORMATION AESTHETICS}

One of the leading figures working with information and aesthetic issues was Max Bense, amongst others such as Abraham Moles. Bense was a German scholar, physicist and philosopher who popularised Claude Shannon's theory of information in Germany. Claiming that the information aesthetic must be conceived of as an exact and experimental science, Bense broke radically with the predominant aesthetics in Germany, which were still rooted in Romanticism.

Bense then took this issue further: "information" was not seen as an obstacle to attaining beauty but, on the contrary, as the byword for a particular aesthetics which supported the general calculability of all objects. He subsequently played a remarkable role in the Hochschule für Gestaltung Ulm, as the inspiration behind the integration of scientific methods into the design process. It was Bense who popularised Shannon's information and mathematical theory of communication (Shannon and Weaver, 1949), known as information theory, in classes between 1954 and 1958. His

Informationsästhetik (Information Aesthetics), written in 1956, used models of communication techniques to break down aesthetic categories into aesthetic processes. Supported by a general hypothesis of the calculability of all objects, Bense's concept was based on the formalisation of aesthetic processes. Every artistic expression and each piece of art was seen as a system of signs and a message. In Bense's point of view, the production and reception of art according to the traditional criteria of proportion, harmony and symmetry, had become obsolete. His work therefore focused on stochastic analysis and the synthesis of structures in discourse and the arts, and how these emerge. 
Above and beyond this analysis, he conceptualised every creative and perceptive act as the realisation of a communicative act between a sender (the work of art) and a receiver (the observer of the art). Thus, Bense played an important role in pioneering the use of information theory. Research into the development of the information aesthetic also shows how the theory underlying aesthetic values based primarily on rational and quantifiable criteria can quickly come up against methodological limits. Despite these limitations, Bense's information aesthetics identifies three changes that still affect discussions of art and architectural production today: (I) displacement of the function of the author's art and architecture and the concept of art and architecture, such as, (2) the concept of subject and object, and (3) the role of the reception of art and architecture [19].

A new situation arose when the first steps were taken to institutionalise information aesthetics. Bense, who was responsible for the Department of Information and Theory, developed the pedagogy to implement quantitative analysis and objective methods in design. This focus became increasingly strong in design methodologies influenced by information theory, cybernetics, operations research and mathematics.

\section{METHODOLOGY: SCIENTIFIC METHODS}

At the HfG the curriculum was academically demanding and included several disciplines related to design, such as the physiology of perception, ergonomics, social psychology, sociology, economics, political science, cultural anthropology, semiotics and information and communication theory, but also traditional subjects, namely the physical and cultural history of art. They were all made relevant to design and the intellectual framework intended to ensure their integration was the philosophy of science, originally taught by Bense. To further enhance the scientific foundation, Maldonado invited several different specialists to teach at the school, such as Horst Rittel, a mathematician, physicist, and sociologist, who taught design methods, information theory and mathematical operations analysis, developing different methods for the "scientifization" of design or "design methods". In the School, all projects and forms of product procedures were interrogated and had to be justified or, failing that, would be judged arbitrary or worse. Rittel served as a kind of a link for transferring scientific and engineering knowledge (developed during and after World War II) to the design professions. His ambition was to master the increasingly complex tasks presented by product design and product modelling and his lessons documenting the discipline referred to what he considered the science of methods, i.e. methodology.

Rittel's first assignment was a lecture on information and communication theory, which everyone at the time thought would be the key to the future. Klaus Krippendorff, who graduated from HfG in 1967, recalls that the philosophy of science became increasingly relevant to design, turning into a 
systematic exploration of the heuristics that designers were using [20]. Horst Rittel's mathematical training gave him access to models, theories, and conceptual frameworks which were little known to ordinary designers. He introduced operations research methods, mathematical decision theory, game theory, systems analysis and planning techniques and thus enriched the repertoire of support methods for design (see figure l4). Rittel's teaching notebook explained the notions of logic and, under his influence, the concept shifted towards that of a designer who would be able to handle heuristic planning and design methods and work on equal terms in product or strategy development teams.

In his initial approaches to the question of method, Rittel focused on two important areas: on the one hand, the real situation and, on the other hand, the desired situation, in which the strategies implicit in the methods, means and tools should be transmitted. He also addressed combinatorics, focusing on the provision of certain elements in certain positions, and divided the technical working out of problems into certain tasks, which he designated in the following order: I.Briefing 2.Verification of conditions regarding logical coherence 3.What does optimal mean? 4. What possible solutions exist? 5. How is "optimal" found here? 6. How should the design work be organised? 7. Means 8 . Experiment verification (see figure 15). The claim that the methodology was based on calculation rules and conversion formulas, namely associativity (representation), commutativity and distributivity, has been verified (see figure 16). Rittel also used these rules of calculation to address the topological signature.

According to Klaus Krippendorff, Rittel made a significant contribution towards establishing a more scientific curriculum at the School by relating science to design and putting the ideology of Tomas Maldonado and the theory of Max Bense into practice. With a background in mathematics, physics, and sociology, Rittel introduced his students and colleagues to a somewhat different perspective by teaching methodology, theory of science, and operations research. He was not a taxonomist who categorised the world, nor a positivist, but a pragmatist in the tradition of Pierce. Full of forceful ideas, his teaching methods were thought to prepare students for designing a more complex world, opening up possibilities for empirical investigation. In fact, he explained that the genesis of his own approach to design methodology emerged when he tried, in around 1960, to apply the new design methods to the field of planning and found that they yielded satisfactory results. This led him to reconsider the foundations of design methodology [4].

Rittel's work emphasised the early planning and preparation phase in design work, based on operations research, systems thinking and the use of information to support decision-making when dealing with complex problems. However, this also involved a significant emphasis on human participation in the social process of decision-making within organisations. It 
was this latter aspect of design, namely the human perspective and social process, which gradually distinguished his approach to design and design methodology from others.

Horst Rittel succeeded in realising a relationship between design and science, putting the ideology of Maldonado and the information aesthetics of Max Bense into practice, thus synthesising and accomplishing the scientific ambition of the Ulm School. In the early '60s before HfG Ulm closed, Rittel moved to the College of Environmental Design at the University of Berkeley as a researcher in scientific project planning methods, working with Christopher Alexander, who had come from Cambridge. The HfG of Ulm, however, had a peculiar relationship with Christopher Alexander. This mentor of the Design Methods Movement and pioneer of computing in architecture became a reference in Ulm since his books dealt with the computer not as a kind of "black box" which provides solutions when fed with programs but instead by focussing on operations involving detailed annotation of algorithms to analyse and synthesise design, making use of flowcharts, graphs and symbolic notation. Using the notation techniques described in his books, the computational logic, which was written down and involved combinations of symbols derived from set
Figure 14: "Methodology" course 1959, Professor Horst Rittel.

Source: HfG Ulm archive, personal photograph, March 2012.

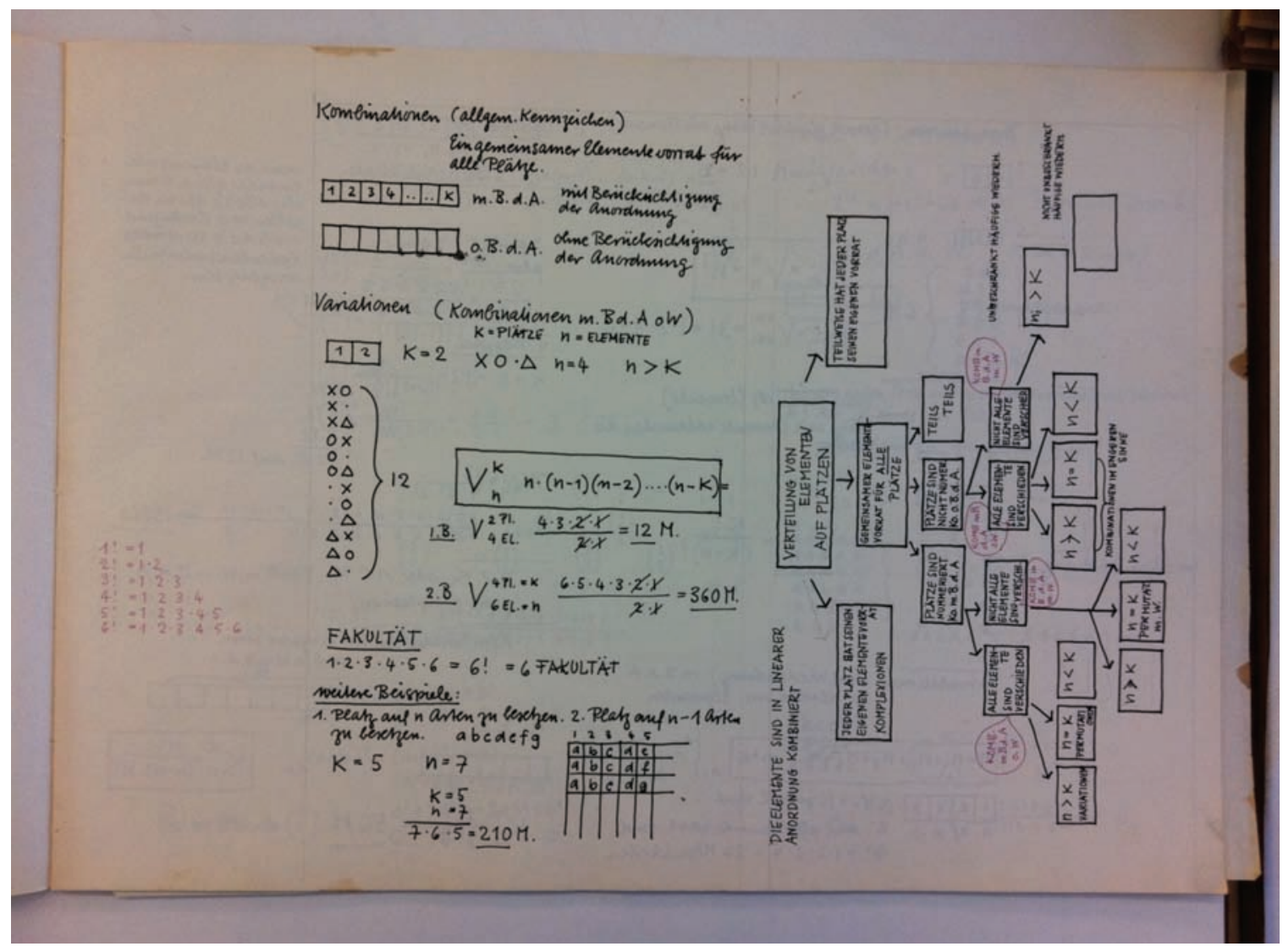




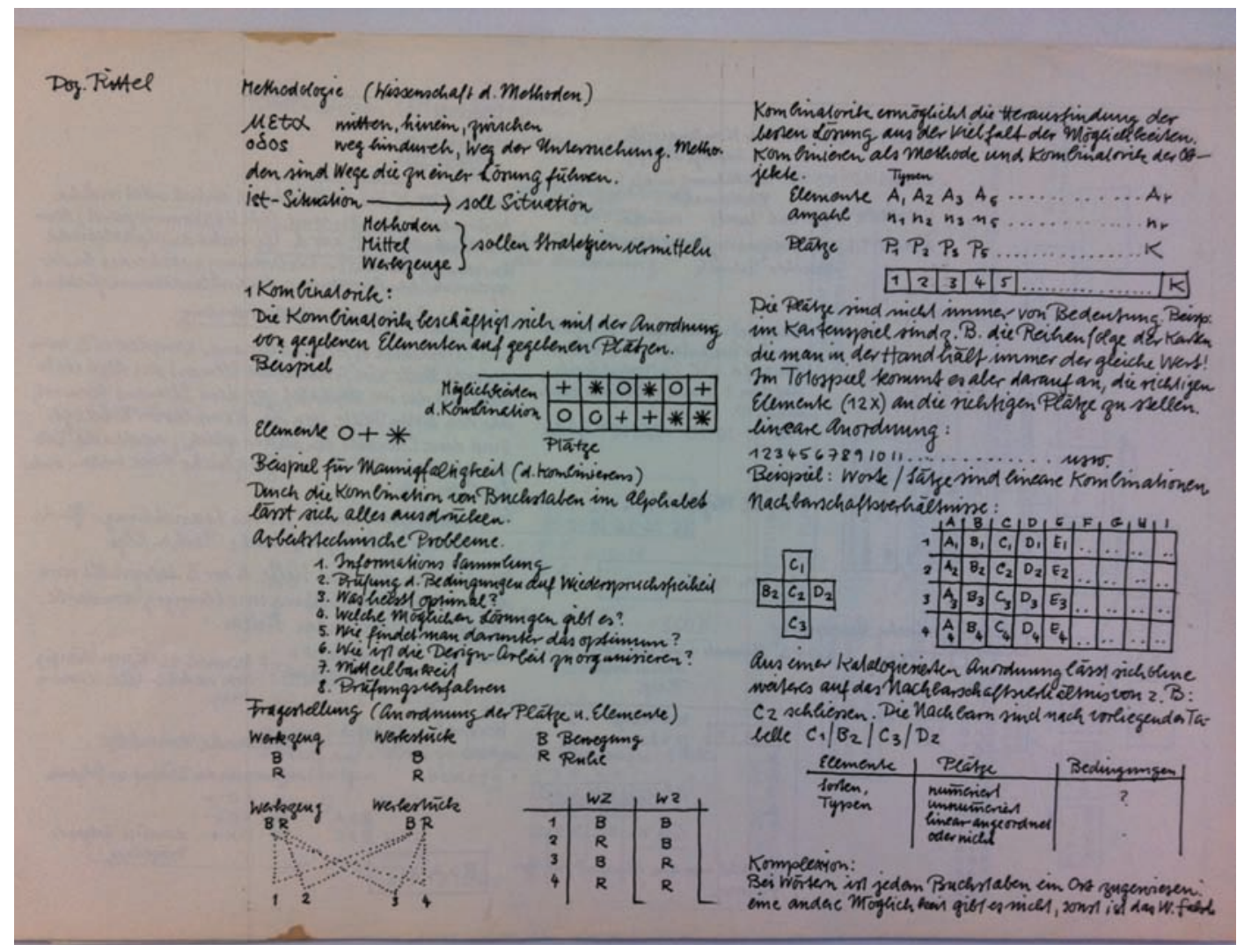

A Figure 15: "Methodology” course 1959, Professor Horst Rittel. Source: HfG Ulm archive, personal photograph, March 2012.

theory, could be shared and discussed in places such as the HfG Ulm, whether computers were physically available or not. In situations where everything revolved around notation and the transmission of instructions and commands, the presence of the instructor was of secondary importance. Thus, given this unusual relationship, Alexander can be discussed within the context of the HfG, even though he was never present at the School.

The two researchers, Rittel and Alexander, also argued for a new philosophical and scientific culture in architecture, aiming to supplant the designer's confidence in "intuition" with explicit and analytical accuracy. In Berkeley, Rittel moved beyond design methods, a systemic view of products, to formulate a theory of strategic reasoning based on conflicting objectives, or wicked problems, defending a vision of the continuity of scientific methods developed at the Ulm School in greater depth. All of this work, based on the principles of the philosophy of science, systems theory, operations research and mathematical logic, was motivated by a concern which Alexander and Rittel described as aesthetic. It was not an interest in the appearance of the object, but a belief in an underlying structure that 
methodologte : rechenregeln $u$. umwandlungeformeln

a) aseozintivgesetz

$$
\begin{aligned}
& x_{1} \wedge\left(x_{2} \wedge x_{3}\right)=\left(x_{1} \wedge x_{2}\right) \wedge x_{3}=x_{1} \wedge x_{2} \wedge x_{3} \\
& x_{1} \vee\left(x_{2} \vee x_{3}\right)=\left(x_{1} \vee x_{2}\right) \vee x_{3} \approx x_{1} \vee x_{2} \vee x_{3}
\end{aligned}
$$

b) komutativgeset:

$$
\begin{aligned}
& x_{1} \wedge x_{2}=x_{2} \wedge x_{1} \\
& x_{1} \vee x_{2}=x_{2} \vee x_{1}
\end{aligned}
$$

c) dintributivgesets

$$
\begin{aligned}
& x_{1} \wedge\left(x_{2} \vee x_{3}\right)=\left(x_{1} \wedge x_{2}\right) \vee\left(x_{1} \wedge x_{3}\right) \\
& x_{1} \vee\left(x_{2} \wedge x_{3}\right)=\left(x_{1} \vee x_{2}\right) \wedge\left(x_{1} \vee x_{3}\right)
\end{aligned}
$$

duslitatsprinzip = eine symmetrie dem sinne nach

beispie1 : 2 punkte bestimmen eine gerade eine gerade bestimnt 2 punkte

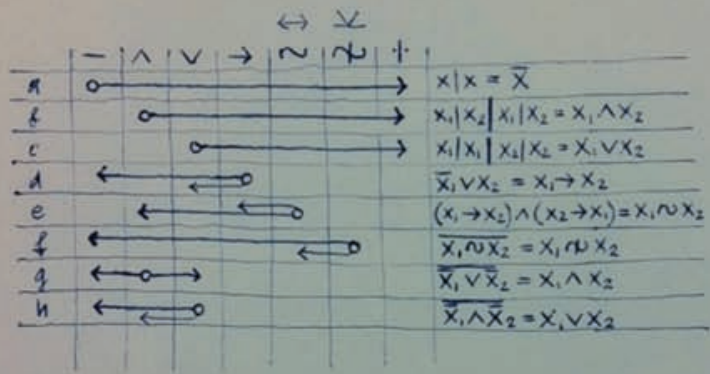

$$
\begin{aligned}
& p \wedge p=p \\
& p \vee p=p \\
& p \wedge \bar{p}=0 \\
& p \vee \bar{p}=1 \\
& p \sim p=1 \\
& p \sim p=0 \\
& p \sim \bar{p}=0 \\
& p \sim \bar{p}=1 \\
& p \rightarrow p=p \\
& p \rightarrow \bar{p}=p
\end{aligned}
$$

FFigure 16: "Topology" course 1959-1962, Professor Horst Rittel. Source: HfG Ulm Archive, personal photograph, March 2012.

reohenregeln :

$$
\begin{aligned}
& \text { A } \overline{\bar{x}}=x \\
& \text { B kommutativgesetze } \\
& \text { C assoziativgesetze } \\
& \text { D distributivgesetze } \\
& \text { B } \overline{x_{1} \wedge x_{2}}=\bar{x}_{1} \vee \bar{x}_{2} \\
& \overline{x_{1} \vee X_{2}}=\bar{x}_{1} \wedge \bar{x}_{2} \\
& \text { F duslitatnprinzip } \\
& x_{1} \rightarrow x_{2}=\bar{x}_{1} \vee x_{2} \\
& x_{1} \leftrightarrow x_{2}=\left(x_{1} \rightarrow x_{2}\right) \wedge\left(x_{2} \rightarrow x_{1}\right) \\
& x_{1} \mid x_{2}=\bar{x}_{1} \wedge x_{2}
\end{aligned}
$$


Figure 17: Synthetic scheme relating "computing without computers" to the disciplines, areas and teachers analysed in this paper.

Source: image owned by the author.

\section{6. “COMPUTATIONAL DESIGN THINKING” WITHOUT THE MACHINE}

In "Looking Back at Ulm", Tomás Maldonado states that Ulm had a pioneering vision of the design process, but lacked a machine - the computer. He says, "But in the midst of our limitless faith in method (...) there lay some powerful intuitions that the evolution of information technology, specially since 1963, has to a large extent confirmed" [2I].

Even before there were computers, a kind of "computing without computers" existed at the HfG and was incorporated into the work of the three protagonists analysed above (see figure 17). At first this development involved a transfer from the sciences and other engineering disciplines to architecture. It was architecture's predisposition towards model making which explains why theoretical and cybernetic information models were, despite their abstract nature, so well-received at places like the Hochschule für Gestaltung in Ulm. Computing without computers allowed for the conceptualisation of the computer, whereas computing with computers transposed the traditional modes of operation and thinking into a new medium. It was computing without computers, analysed in this paper with reference to the Ulm School, that led to a radical shift in the understanding of subject and object which, in turn, led to a radical rethinking of the production of form [19].

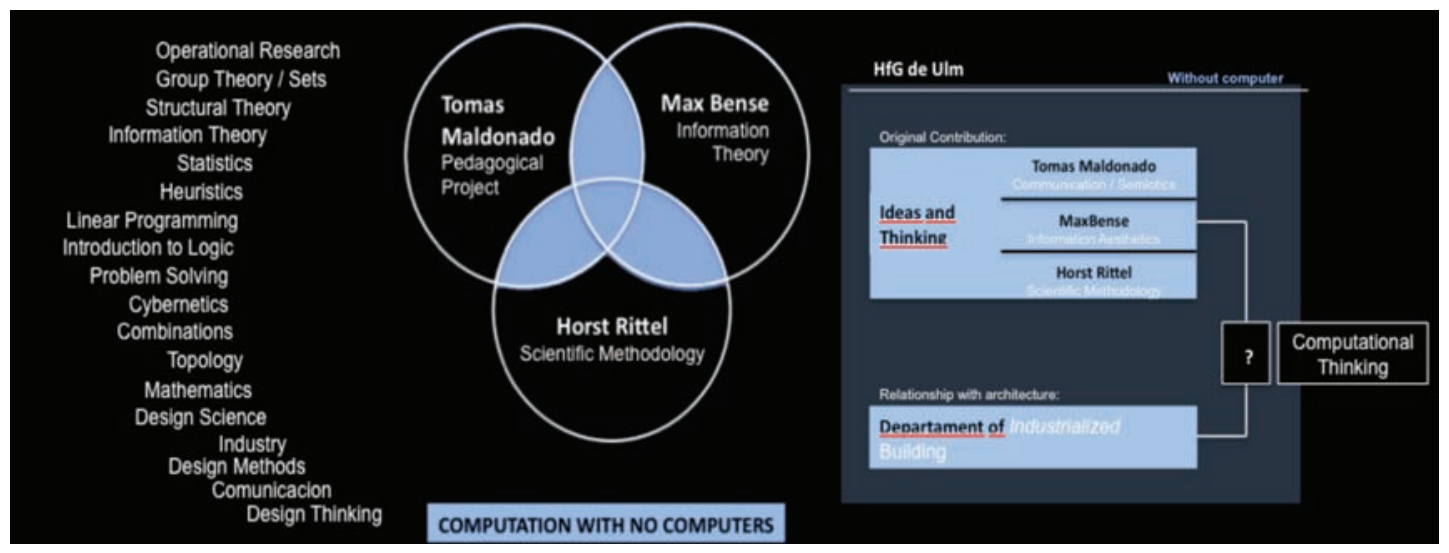

\section{CONCLUSION}

The teaching at the HfG Ulm promoted a different approach to the design process. Instead of focusing on the design and development of specific and finite forms, students sought to exploit the definition of geometric design rules to control the generation of form(s). Thus, by reflecting a scientific methodology, the design practice began to embrace the concept of systems, in which sets of interdependent information are structured to control the 
generation of design solutions. The exercises involving geometric patterns were clear examples of this system-based approach. They show how students think about a set of variation rules for a given geometric module and subsequently conceive of geometric patterns in which the module is no longer a fixed and repetitive entity, but instead an element that varies geometrically in each instance. Although these constructions were handdrawn, they already reflected a mode of computational design thinking similar to the parametric design approaches of contemporary architecture. By extending the manual possibilities, the computer can expand the idea of design systems to a greater level of flexibility and complexity. On the one hand, by digitally programming the rule-based design system, the designer can generate, view, evaluate and change his ideas in real time and thus refine the quality of the solutions. Moreover, the calculation power of the computer enables it to deal with more complex design algorithms, which would be very difficult to conceive of and implement using only mental and manual design processes.

In conclusion, it can be argued that a new understanding of design teaching was developed at the HfG Ulm. In the mid 60s it pioneered heuristic procedures that were related to the power of the new computational methods. It involved a scientific approach based on information processing design research methods, driven by a visual aesthetic. All of these interests, based on the principles of the philosophy of science, systems theory, operational research and mathematical logic, were directed towards another central goal: the aesthetic aspect. This reflected an interest in the superficial appearance of the object, but also a belief in the underlying structure which mathematics or logic tries to capture. In short, the reformulation of design pedagogy emerging from Ulm, informed by information theory and scientific method, constituted a legacy for computational thinking, later implemented via the avant-garde architecture of the 60 s and 70 s using other means of computation, and generalised and extended in today's algorithmic architecture.

\section{ACKNOWLEDGMENTS}

The authors wishes to thank the staff at the HfG Archive at Ulm, the Fundação para a Ciência e a Tecnologia (FCT) in Portugal, and Tomas Maldonado for kindly sharing his memories.

\section{REFERENCES}

I. Rocha, J.;A.: Architecture Theory 1960-1980: Emergence OfA Computational Perspective, Phd Dissertation, Massachusetts Institute Of Technology, 2004.

2. Petruschat,J.; Form+Zweck $20 \mathrm{Hfg}$ Ulm,By Angelika Petruschat, Till Bruttel, Chupfriemert And Jörgpetruschat, 2003.

3. Frampton, K., Apropos Ulm: Curriculum And Critical Theory, Inthe Mitpress, Ed., Oppositions New York, Nº 3; 1974, I7-36. 
4. Buchanan, R., Thinking About Design: A Historical Perspective, In Meijers, Anthonie And Gabbay, Dov. (Ed.), The Handbook OfTechnology And Engineering Sciences, Elsevier Press, New York. 2009, 427-428.

5. Maldonado, T., Looking Back At Ulmin Herbert Lindinger Ulm Design:The Morality Of Objects. Hochschulefrgestaltung Ulm, 1953-1958. Cambridge, Mass: Mit Press. 1991, 222.

6. Spitz, Rene, 2012, The Genius That Was Ulm Heller, by Steven Heller, November 26, 2012. in http://www.printmag.com/design-education/the-genius-that-was-ulm/.[I-92013].

7. Maldonado,T.; Is The Bauhaus Relevant Today In Ulm?, In Ulm 8/9, September, I963, 12.

8. Huff,W.; Albers, Bill E Maldonado: Il Corsofondamentaledellascuola Di Design Di Ulm (HfG) In Aavv Tomas Maldonado, Architecture Monograhs; Skira,2009.

9. Maldonado, T.; Principles OfThe Basic Course 1955, HfG Archive, Ulm; 1955.

10. Maldonado, T., Interviewed By The Author For Her Phd Research On The Hochschulefür Gestaltung of Ulm, (Milan 2012). Maldonado, Tomas 20I2: Interviewed By Isa Clara Neves, Milan (Unpublished Document).

I I. Krampen, M. and Hormann, G.; Die Hochschule fur Gestaltung Ulm/The School of Design. Beginnings of a Project of Radical Modernism. Berlin, 2003, I0I103.

12 Fröshaug, A.,Visuelle Methodik, Ulm 4, 1959, 61.

13. Maldonado, T., Bonsiepe, G., Science And Design Ulm 10/II, 1964, 10.

14. Maldonado, T., New Developments In Industry And The Training OfThe Designer, Ulm 2.; 1958.

15. Maldonado, T.,Communication and Semiotics, in Ulm 5, 1958, 69-78.

16. March, L.: Editorial, Environment and Planning B,Volume 3, 1976, I-3.

17. Maldonado, T.; "Glossário De Semiótica” in Uppercase 5 HfG Ulm. Edited By Theo Crosby. London:Whitefriars Press Tonbridge Kent, 1959/60.

18. Maldonado,T. Bonsiepe G. (1960/6I), Symbol System for Electronic Data Processing Machines 1960/196I Ulm 8/9 (September 1963): 20-24, 22

19. Rocker, l.; Emerging Structures: Information Aesthetics And Architecture OfThe Digital Medium, Phd Dissertation, Princeton University. 2010.

20. Krippendorff, K.; The Semantic Turn: A New Foundation For Design. Taylor \& Francis Crc, London. P.3। I, 2006.

21. Maldonado, T.: Looking Back at Ulm, in: Lindinger, H., Ulm Design: the Morality of Objects. Hochschule fur Gestaltung Ulm, 1953-1958. Mass: MIT Press, Cambridge, I99|, 222.

\section{Isabel Clara Neves, João Rocha and José Pinto Duarte}

Isabel Clara Neves

20093022@fa.lisboa.pt

University of Lisbon

Department of Architecture

CIAUD

Research Centre for Architecture, Urban Planning and Design

Rua Sá Nogueira | Pólo Universitário

Alto da Ajuda |I349-055 Lisboa 
